\title{
Inhibition of vesicular glutamate storage and exocytotic release by Rose Bengal
}

\author{
Kiyokazu Ogita, ${ }^{*}, 1$ Koji Hirata,* David G. Bole,* Sumiko Yoshida, ${ }^{, 2}$ Yutaka Tamura,*,3 \\ Anne Marie Leckenby* and Tetsufumi Ueda* $\dagger+$ \\ *Mental Health Research Institute, Departments of $\uparrow$ Pharmacology and $\ddagger$ Psychiatry, Medical School, The University of Michigan, \\ Ann Arbor, Michigan, USA
}

\begin{abstract}
It had been thought that quantal size in synaptic transmission is invariable. Evidence has been emerging, however, that quantal size can be varied under certain conditions. We present evidence that alteration in vesicular $\left[{ }^{3} \mathrm{H}\right] \mathrm{L}$-glutamate (Glu) content within the synaptosome (a pinched-off nerve ending preparation) leads to a change in the amount of exocytotically released $\left[{ }^{3} \mathrm{H}\right] \mathrm{Glu}$. We found that Rose Bengal, a polyhalogenated fluorescein derivative, is a quite potent membrane-permeant inhibitor $\left(K_{\mathrm{i}}=19 \mathrm{~nm}\right)$ of glutamate uptake into isolated synaptic vesicles. This vesicular Glu uptake inhibition was achieved largely without affecting $\mathrm{H}^{+}$pump ATPase. We show that various degrees of reduction elicited by Rose Bengal in $\left[{ }^{3} \mathrm{H}\right] \mathrm{Glu}$ in synaptic vesicles inside
\end{abstract}

the synaptosome result in a corresponding decrease in the amount of $\left[{ }^{3} \mathrm{H}\right] \mathrm{Glu}$ released in a depolarization- (induced by 4aminopyridine) and $\mathrm{Ca}^{2+}$-dependent manner. In contrast, fluorescein, the halogen-free analog of Rose Bengal, which is devoid of inhibitory activity on vesicular $\left[{ }^{3} \mathrm{H}\right] \mathrm{Glu}$ uptake, failed to change the amount of exocytotically released $\left[{ }^{3} \mathrm{H}\right] \mathrm{Glu}$. These observations suggest that glutamate synaptic transmission could be altered by pharmacological intervention of glutamate uptake into synaptic vesicles in the nerve terminal, a new mode of synaptic manipulation for glutamate transmission.

Keywords: glutamate, inhibitor, release, Rose Bengal, vesicular uptake.

J. Neurochem. (2001) 77, 34-42.
The common biochemical L-glutamate $(\mathrm{Glu})$ is now widely recognized as the major excitatory neurotransmitter in the vertebrate CNS (Fonnum 1984; Cotman et al. 1988; Watkins et al. 1990). Proper Glu transmission plays a key role in physiological brain functions such as learning and memory formation, as well as basic neural communication (Cotman et al. 1988; Collingridge and Singer 1990), whereas aberrant Glu transmission appears to be involved in various neurological and psychiatric disorders, such as certain forms of epilepsy, ischemic brain injury, Parkinson's disease, Alzheimer's disease and schizophrenia (Meldrum 1985; Choi 1988; Javitt and Zukin 1991; Zorumski and Olney 1993; Lipton and Rosenberg 1994; Bradford 1995; Bunney et al. 1995; Olney and Farber 1995; Coyle 1996; Chapman 1998). Presynaptically, synaptic vesicles play a pivotal role in Glu synaptic transmission (Ueda 1986; Nicholls 1989; Maycox et al. 1990; Özkan and Ueda 1998). L-Glutamate is accumulated into isolated synaptic vesicles in a highly specific and ATP-dependent manner, utilizing the electrochemical proton gradient generated by V-type proton-pump ATPase (Naito and Ueda 1983, 1985; Maycox et al. 1988; Cidon and Sihra 1989; Fykse et al. 1989; Tabb et al. 1992), and has been shown to be concentrated in synaptic vesicles in vivo (Storm-Mathisen et al. 1983; Burger et al. 1989). Under normal physiological conditions, Glu is released from synaptic vesicles in the nerve terminal by a $\mathrm{Ca}^{2+}$-signaled exocytotic mechanism, but not from the

Received November 17, 2000; accepted November 21, 2000.

Address correspondence and reprint requests to Dr T. Ueda, Mental Health Research Institute, The University of Michigan, 205 Zina Pitcher Place, Ann Arbor, MI 48109-0720, USA. E-mail: tueda@umich.edu.

${ }^{1}$ The permanent address of Kiyokazu Ogita is Department of Pharmacology, School of Pharmaceutical Sciences, Setsunan University, Hirakata, Osaka, Japan.

${ }^{2}$ The permanent address of Sumiko Yoshida is Department of Psychiatry, Medical School, Tohoku University, Sendai, Japan.

${ }^{3}$ The permanent address of Yutaka Tamura is Department of Pharmacology, School of Pharmaceutical Sciences, Fukuyama University, Fukuyama, Japan.

Abbreviations used: 4-AP, 4-aminopyridine; Asp, L-aspartate; FCCP, carbonyl cyanide $p$-(trifluoromethoxy)-phenylhydrazone; Glu, L-glutamate; RCSV, rat crude synaptic vesicles. 
cytoplasmic pool (Nicholls and Sihra 1986; Kish and Ueda 1991; McMahon and Nicholls 1991; Mehta et al. 1996). Vesicular accumulation of Glu is thought to play a crucial role in directing the common biochemical Glu to the neurotransmitter pathway, diverting it from the general metabolic pathway (Ueda 1986; Özkan and Ueda 1998).

It has been reported that vesicular glutamate uptake is inhibited by certain glutamate analogs (Naito and Ueda 1985; Winter and Ueda 1993), ergopeptides (Carlson et al. 1989; Moriyama et al. 1991) and kynurenate-related compounds (Fykse et al. 1992; Bartlett et al. 1998; Carrigan et al. 1999). Roseth et al. (1995, 1998) found that xenobiotic, anionic dyes, such as Evans Blue, Chicago Sky Blue 6B and Trypan Blue, are potent competitive inhibitors of Glu uptake into isolated synaptic vesicles. Özkan et al. (1997) showed that an elongated protein, referred to as IPF, inhibits vesicular glutamate uptake with high potency. However, it remains to be seen whether any of the compounds mentioned above is effective, when applied extracellularly, in leading to a decrease in Glu released upon stimulation of the nerve terminal. A substance which is taken up into nerve endings and affects vesicular Glu storage would provide a new way of manipulating the amount of evoked release of Glu. Demonstration of such an agent may stimulate a new approach to developing lead compounds for creating therapeutically useful agents targeting certain CNS diseases involving abnormal Glu synaptic transmission.

Here we report that the hydrophobic, membrane-permeant dye Rose Bengal, a polyhalogenated fluorescein derivative, is remarkably potent in inhibiting Glu uptake into isolated synaptic vesicles. We present evidence that, when incubated with synaptosomes, Rose Bengal causes a dose-dependent reduction in vesicular Glu content and diminishes the amount of exocytotically released Glu.

\section{Materials and methods}

\section{Preparation of synaptic vesicles and synaptosomes}

Rat crude synaptic vesicles (RCSV) were prepared as described by Kish and Ueda (1989), with minor modifications. ATP-dependent Glu uptake activity was generally $400-500 \mathrm{pmol} / \mathrm{mg} / 10 \mathrm{~min}$ under our standard assay conditions, and represented $85-90 \%$ of the total activity (i.e. activity in the presence of ATP) in the RCSV.

Crude synaptosomes were prepared using a modification of the method of Krueger et al. (1977) from male Sprague-Dawley rat $(200-250 \mathrm{~g})$ cerebrum. The final pellets were then suspended by gently pipetting in $15 \mathrm{~mL}$ of oxygenated $\left(\begin{array}{llll}95 \% & \mathrm{O}_{2} / 5 \% & \mathrm{CO}_{2}\end{array}\right)$ artificial CSF, consisting of $124 \mathrm{~mm} \mathrm{NaCl}, 5 \mathrm{~mm} \mathrm{KCl}, 2 \mathrm{~mm}$ $\mathrm{MgSO}_{4}, 1.25 \mathrm{~mm} \mathrm{NaH} \mathrm{PO}_{4}, 2 \mathrm{~mm} \mathrm{CaCl}, 22 \mathrm{~mm} \mathrm{NaHCO}{ }_{3}$ and $10 \mathrm{~mm}$ D-glucose. These suspensions were used as the synaptosomal preparation within $8 \mathrm{~h}$ for the studies described here. These procedures were all carried out at $4^{\circ} \mathrm{C}$ or on ice. The synaptosomal preparations contained proteins at a concentration of $1-1.5 \mathrm{mg} / \mathrm{mL}$.
Protein concentrations were determined using the Coomassie Protein Assay kit from Pierce, with bovine serum albumin as standard. Buffers and any other solutions used in this study were all sterilized immediately before use by filtration through a nitrocellulose membrane (pore size $0.45 \mu \mathrm{m}$ ), to avoid possible microbial contamination (Yoneda and Ogita 1989).

\section{L-Glutamate uptake into synaptic vesicles}

Vesicular Glu uptake was assayed as described previously by Naito and Ueda $(1983,1985)$ with minor modifications. Aliquots (30$40 \mu \mathrm{g}$ ) of RCSV were incubated at $30^{\circ} \mathrm{C}$ with $50 \mu \mathrm{M}\left[{ }^{3} \mathrm{H}\right] \mathrm{Glu}(\mathrm{a}$ specific activity of $7.4 \mathrm{GBq} / \mathrm{mmol}$ was obtained by addition of unlabeled Glu to $\left[\mathrm{G}^{-}{ }^{3} \mathrm{H}\right] \mathrm{Glu}$ with a specific activity of $2.33 \mathrm{TBq} /$ mmol, Amersham Life Science, Buckinghamshire, UK) in $0.1 \mathrm{~mL}$ of an incubation medium ( $\mathrm{pH} 7.4)$ containing $20 \mathrm{mM}$ HEPES$\mathrm{KOH}, 0.25 \mathrm{M}$ sucrose, $4 \mathrm{~mm} \mathrm{MgSO}_{4}, 4 \mathrm{~mm} \mathrm{KCl}$ and $2 \mathrm{~mm}$ L-aspartic acid (Asp) in the absence or presence of $2 \mathrm{~mm}$ ATP (adjusted pH 7.4 by addition of Tris-base). For Lineweaver-Burk analysis, aliquots of RCSV were incubated with $\left[{ }^{3} \mathrm{H}\right] \mathrm{Glu}(74 \mathrm{kBq} /$ tube) at $30^{\circ} \mathrm{C}$ for $2 \mathrm{~min}$ in the presence of seven different concentrations of unlabeled Glu to cover a concentration range of 0.2-5 mM. Prior incubation without ATP, unlabeled Glu and $\left[{ }^{3} \mathrm{H}\right] \mathrm{Glu}$ was for $30 \mathrm{~min}$ at $30^{\circ} \mathrm{C}$. ATP-dependent Glu uptake activity was calculated by subtracting uptake activity in the absence of ATP from that in its presence. Test compounds Rose Bengal and fluorescein (Aldrich Chemicals, Milwaukee, WI, USA) were preincubated at $30^{\circ} \mathrm{C}$ for $30 \mathrm{~min}$ with RCSV in the incubation medium lacking $\left[{ }^{3} \mathrm{H}\right] \mathrm{Glu}$, unlabeled Glu and ATP. All compounds tested were dissolved in dimethylsulfoxide at a concentration of $5 \mathrm{~mm}$; the concentration of Rose Bengal, fluorescein and other fluorescein analogs was determined spectrophotometrically. The final concentration of dimethylsulfoxide in reaction mixtures was kept at $1 \%$ or less.

\section{L-Glutamate release from synaptosomes}

Aliquots $(0.15-0.23 \mathrm{mg}$ of protein) of synaptosomal preparations were incubated with $50 \mathrm{~nm}\left[{ }^{3} \mathrm{H}\right] \mathrm{Glu}(2.33 \mathrm{TBq} / \mathrm{mmol})$ in $1.5 \mathrm{~mL}$ $\mathrm{CSF}$ at $37^{\circ} \mathrm{C}$ for $10 \mathrm{~min} .\left[^{3} \mathrm{H}\right] \mathrm{Glu}$-loaded synaptosomal suspensions $(1.2 \mathrm{~mL})$ were layered onto cellulose acetate membrane filters (pore size $0.45 \mu \mathrm{m}$ ) placed in a superfusion chamber. The synaptosomes were superfused $(0.6 \mathrm{~mL} / \mathrm{min})$ with CSF for $40 \mathrm{~min}$ before being subjected to depolarization with $50 \mu \mathrm{M}$ 4-aminopyridine (4-AP; Sigma, St Louis, MO, USA). When $\mathrm{Ca}^{2+}$-independent release was monitored, EGTA was substituted for $\mathrm{CaCl}_{2}(2 \mathrm{mM})$ in $\mathrm{CSF}$. These procedures were all carried out at $37^{\circ} \mathrm{C}$. In general, three 30-s fractions containing Glu released by depolarization with 4-AP were collected. Prior to this, three 30 -s fractions were collected. The release observed during this period was defined to represent basal release. Evoked release was calculated by subtracting the amount of $\left[{ }^{3} \mathrm{H}\right] \mathrm{Glu}$ released during the basal release period $(1.5 \mathrm{~min})$ from the amount of $\left[{ }^{3} \mathrm{H}\right] \mathrm{Glu}$ released during the $1.5-\mathrm{min}$ period after 4-AP application. In some experiments, fractions were collected every $10 \mathrm{~s}$ in order to improve time resolution. The amount of release into each fraction was expressed as a percentage of either the total $\left[{ }^{3} \mathrm{H}\right] \mathrm{Glu}$ taken up into synaptosomes at the end of 10-minute loading or the amount of $\left[{ }^{3} \mathrm{H}\right] \mathrm{Glu}$ collected during the basal release period. The total $\left[{ }^{3} \mathrm{H}\right] \mathrm{Glu}$ loaded into synaptosomes was estimated from the amount of $\left[{ }^{3} \mathrm{H}\right] \mathrm{Glu}$ in $0.1 \mathrm{~mL}$ of loaded synaptosomes, determined by the same filtration method used for 
the vesicular Glu uptake assay. Compounds tested were coincubated with synaptosomes during $\left[{ }^{3} \mathrm{H}\right]$ Glu loading. Similar experiments indicated that at least $85 \%$ of radioactivity released was recovered as Glu (Feasey et al. 1986). Under our experimental conditions, at least $90 \%$ of radioactivity recovered in the vesicle fraction was attributable to $\left[{ }^{3} \mathrm{H}\right] \mathrm{Glu}$.

\section{L-Glutamate content in synaptic vesicles within the synaptosome}

Aliquots $(0.1-0.15 \mathrm{mg}$ of protein) of synaptosomal preparations were incubated in $1.5-\mathrm{mL}$ microtubes with $50 \mathrm{~nm}\left[{ }^{3} \mathrm{H}\right] \mathrm{Glu}$ (2.33 TBq/mmol) in $1 \mathrm{~mL} \mathrm{CSF}$ at $37^{\circ} \mathrm{C}$ for $10 \mathrm{~min}$, followed by centrifugation at $16000 g_{\max }$ for $5 \mathrm{~min}$ using a Beckman Microfuge. After thorough removal of the supernatants, the pellets were homogenized in $6 \mathrm{~mm}$ Tris-maleate $(\mathrm{pH} 8.1)$ containing $2 \mathrm{~mm}$ Asp, using an ultrasonic homogenizer (4710 series, Cole-Palmer Instruments, Chicago, IL, USA) for $3 \mathrm{~s}$, in order to lyse $\left[{ }^{3} \mathrm{H}\right] \mathrm{Glu}-$ loaded synaptosomes. As a control, the pellets were suspended in CSF containing $2 \mathrm{~mm}$ Asp by extremely gentle pipetting or by using a plastic homogenizing pestle. These suspensions were kept on ice for $45 \mathrm{~min}$ and subsequently centrifuged at $16000 \mathrm{~g}_{\max }$ for 5 min. The supernatants were put onto a Whatman GF/C filter under a constant vacuum of $10 \mathrm{mmHg}$ in order to trap synaptic vesicles; the filter was rinsed four times with $2.5 \mathrm{~mL}$ of ice-cold $0.15 \mathrm{M} \mathrm{KCl}$. In some experiments, the supernatants obtained upon bursting $\left[{ }^{3} \mathrm{H}\right] \mathrm{Glu}$-loaded synaptosomes were centrifuged for $60 \mathrm{~min}$ at $200000 g_{\max }(50000$ r.p.m., Beckman 70.1Ti rotor) to pellet synaptic vesicles. Radioactivity $(V$ ) retained on the filter or in the synaptic vesicle pellet was measured by scintillation spectrophotometry and divided by the total $\left[{ }^{3} \mathrm{H}\right] \mathrm{Glu}(S)$ in synaptosomes at the time of loading. The total $\left[{ }^{3} \mathrm{H}\right] \mathrm{Glu}$ loaded into synaptosomes was estimated from the amount of $\left[{ }^{3} \mathrm{H}\right] \mathrm{Glu}$ in $0.1 \mathrm{~mL}$ of loaded synaptosomes, determined by the filtration method. Vesicular Glu content was expressed as:

$\left(V_{\text {lysed }}-V_{\text {unlysed }}\right) / S$.

Neither $V_{\text {lysed }}$ nor $V_{\text {unlysed }}$ was affected by the presence of Glu (2 mM) or Asp (2 mM) in the lysing solution. However, the former, but not the latter, was reduced substantially by carbonyl cyanide $p$-(trifluoromethoxy)-phenylhydrazone (FCCP; $20 \mu \mathrm{M}$ ), indicating that $V_{\text {lysed }}$ but not $V_{\text {unlysed }}$ represents $\left[{ }^{3} \mathrm{H}\right] \mathrm{Glu}$ associated with the synaptic vesicle. Compounds tested were incubated with synaptosomes for the same period as for loading $\left[{ }^{3} \mathrm{H}\right] \mathrm{Glu}$.

\section{Depolarization-induced calcium influx into synaptosomes}

Aliquots $\left(10 \mu \mathrm{g}\right.$ protein) of synaptosomes were incubated at $37^{\circ} \mathrm{C}$ for 1.5 or $10 \mathrm{~min}$ in a solution (final volume, $0.1 \mathrm{~mL}$ ) containing ${ }^{45} \mathrm{Ca}(3 \mu \mathrm{Ci})$ and unlabeled $50 \mathrm{nM}$ Glu with or without $50 \mu \mathrm{M} 4-\mathrm{AP}$ in $\mathrm{Ca}^{2+}$-containing CSF. 4-Aminopyridine-induced calcium influx into synaptosomes was terminated by diluting with $2.5 \mathrm{~mL}$ of ice-cold $0.15 \mathrm{M} \mathrm{KCl}$, and the amount of ${ }^{45} \mathrm{Ca}$ taken up was determined by the same method described for Glu uptake into synaptic vesicles.

\section{ATPase activity in synaptic vesicles}

ATPase activity in RCSV was assayed by determination of free inorganic phosphate liberated through incubation of RCSV with ATP, according to Lanzetta et al. (1979), with minor modifications.
In brief, aliquots (40-50 $\mu \mathrm{g})$ of RCSV were incubated in $0.1 \mathrm{~mL}$ of the same incubation medium used for the assay for vesicular uptake, in either the presence or absence of $2 \mathrm{~mm} \mathrm{ATP}$ at $30^{\circ}$ for $10 \mathrm{~min}$. An aliquot $(25 \mu \mathrm{L})$ of the reaction mixture was added to $0.2 \mathrm{~mL}$ of an ice-cold solution containing $0.034 \%$ malachite green hydrochloride (Sigma), $1 \%\left(\mathrm{NH}_{4}\right)_{6} \mathrm{Mo}_{7} \mathrm{O}_{24} \cdot 4 \mathrm{H}_{2} \mathrm{O}, 0.2 \%$ Tween-40 and $1 \mathrm{M} \mathrm{HCl}$, followed by addition of $25 \mu \mathrm{L}$ of $34 \%$ sodium citrate $2 \mathrm{H}_{2} \mathrm{O}$. The synaptic vesicle fraction was pre-incubated with test compounds at $30^{\circ} \mathrm{C}$ for $30 \mathrm{~min}$ in the incubation medium prior to addition of ATP.

\section{Measurement of membrane potential}

Generation of the membrane potential across the synaptic vesicle membrane (positive inside) was monitored by fluorescence quenching of the membrane potential-sensitive dye oxanol V, with excitation and emission wavelengths of 600 and $630 \mathrm{~nm}$, respectively, using a Fluorolog III fluorospectrophotometer. The incubation mixture (final volume, $1.5 \mathrm{~mL}$ ) contained $20 \mathrm{~mm}$ HEPES-KOH (pH 7.4), $150 \mathrm{~mm}$ potassium gluconate, $4 \mathrm{~mm} \mathrm{MgSO}_{4}, 1.3 \mu \mathrm{M}$ oxanol V, synaptic vesicles $(50 \mu \mathrm{g} / \mathrm{mL}$ ) and $2 \mathrm{~mm}$ ATP (adjusted to $\mathrm{pH} 7.4$ with Tris-base). The mixture without ATP was preincubated at $30^{\circ} \mathrm{C}$ until oxanol $\mathrm{V}$ equilibrated with synaptic vesicles, as judged by no significant change in fluorescence intensity. Addition of ATP (in $15 \mu \mathrm{L}$ ) caused rapid fluorescence quenching. This was followed by addition of the proton ionophore FCCP $(1 \mu \mathrm{L}$ of $12.5 \mathrm{~mm}$ stock in ethanol), which caused dequenching of the fluorescence, indicating that ATP addition led to generation of the membrane potential. Various amounts of Rose Bengal (in a fixed volume of $3 \mu \mathrm{L}$ dimethylsulfoxide) were added to the incubation mixture after formation of the membrane potential; Rose Bengal exhibited concentration-dependent fluorescence quenching. Addition of FCCP led to varying amounts of dequenching, depending upon the concentration of Rose Bengal. The membrane potential in the absence or presence of Rose Bengal was expressed in terms of fractional quenching as defined:

fractional quenching $=\left(F_{\mathrm{d}}-F_{\mathrm{t}}\right) / F_{\mathrm{o}}$,

where $F_{\mathrm{o}}$ is the fluorescence intensity of oxanol $\mathrm{V}$ observed after addition of synaptic vesicles, $F_{\mathrm{t}}$ the fluorescence intensity observed after addition of the test agent Rose Bengal on top of ATP or addition of ATP alone, and $F_{\mathrm{d}}$ the fluorescence intensity observed after addition of the membrane potential dissipater FCCP.

\section{Statistical analysis}

Results are represented as mean \pm SEM and statistical significance was determined using the two-tailed Student's $t$-test. IC $_{50}$ values were estimated using the Macintosh DELTAGRAPH program, with nonlinear regression analysis. Analysis of Lineweaver-Burk plot and initial rate of uptake was performed using the IBM EXCEL program, with linear regression analysis.

\section{Results}

\section{Inhibition of vesicular Glu uptake}

We tested a variety of membrane-permeant organic compounds, focusing in particular on fluorescein derivatives, for the ability to inhibit glutamate uptake into isolated synaptic 


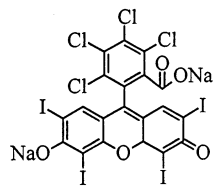

Rose Bengal

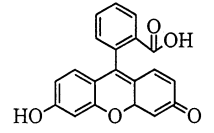

Fluorescein
Fig. 1 Chemical structure of Rose Bengal and fluorescein.

vesicles. We found that Rose Bengal (tetraiodo-tetrachlorofluorescein) is one of the most potent inhibitors of all the agents tested, whereas fluorescein is the least potent. Figure 1 shows the chemical structure of Rose Bengal and fluorescein. Figure 2 shows that Rose Bengal inhibited ATP-dependent vesicular Glu uptake in a concentrationdependent manner at concentrations $>10 \mathrm{nM}$, whereas fluorescein exhibited no significant inhibition up to $3 \mu \mathrm{M}$. The $\mathrm{IC}_{50}$ value of Rose Bengal was determined to be $37 \pm 7 \mathrm{~nm} \quad(n=11)$. Although ATP-independent Glu uptake into RCSV was $<15 \%$ of total uptake, Rose Bengal had no significant effect on ATP-independent Glu uptake at concentrations up to $1 \mu \mathrm{M}$ (data not shown); however, it caused $\approx 50 \%$ inhibition at $50 \mu \mathrm{M}$.

Figure 3 shows a time course of vesicular Glu uptake in the absence or presence of Rose Bengal or fluorescein, following the standard 30-min pre-incubation with test compounds. In the absence of test compounds, Glu uptake increased linearly up to $1.5 \mathrm{~min}$ of incubation time and reached equilibrium at $5 \mathrm{~min}$. Rose Bengal was effective in

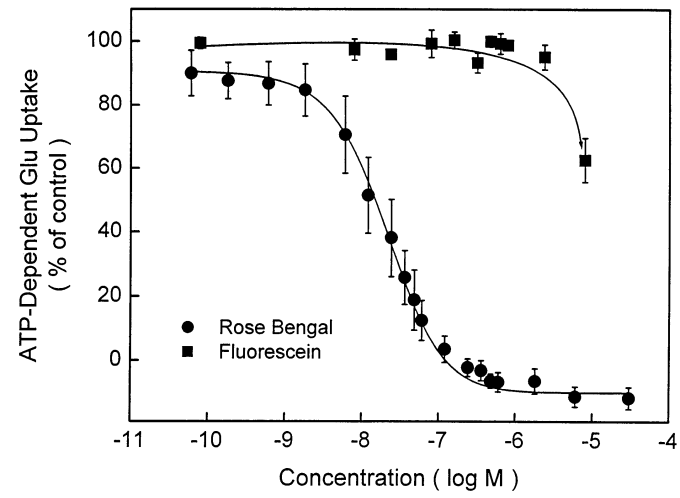

Fig. 2 Effect of various concentrations of Rose Bengal and fluorescein on ATP-dependent Glu uptake into synaptic vesicles. Rat crude synaptic vesicles were incubated in the absence or presence of indicated concentrations (final concentration) of Rose Bengal and fluorescein, and assayed for ATP-dependent Glu uptake, as described in Materials and methods. Uptake activity was expressed as percentage of control value obtained in absence of test compounds. Values were mean \pm SEM from four to six independent experiments. Control values for Rose Bengal and fluorescein dose-response curves were: $500 \pm 18$ and $432 \pm 23 \mathrm{pmol} / \mathrm{mg}$ protein $/ 10 \mathrm{~min}$, respectively.

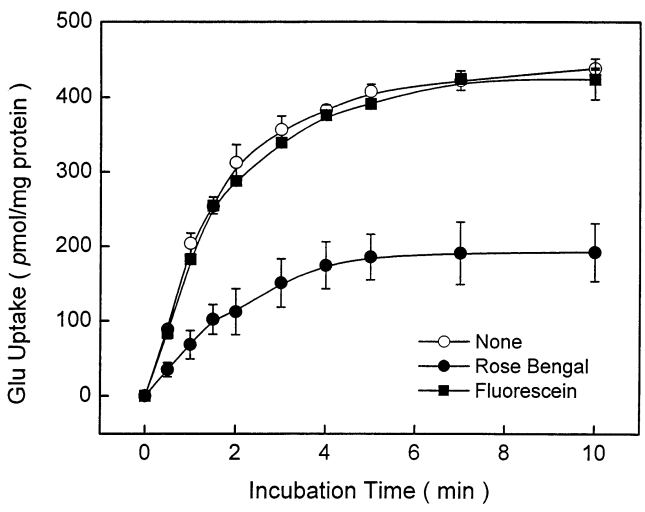

Fig. 3 Effect of Rose Bengal and fluorescein on the time course of vesicular Glu uptake. Following pre-incubation of RCSV with or without Rose Bengal or fluorescein $(100 \mathrm{~nm})$ at $30^{\circ} \mathrm{C}$ for $30 \mathrm{~min}$, a mixture of ATP and $\left[{ }^{3} \mathrm{H}\right]$ Glu was added to initiate vesicular $\left[{ }^{3} \mathrm{H}\right] \mathrm{Glu}$ uptake; uptake was allowed to occur for the various periods indicated. Values indicate uptake activity in the presence of ATP, determined in four separate experiments (mean \pm SEM).

inhibiting Glu uptake throughout the incubation times examined; it reduced not only the initial rate but also the final level of uptake. Half time for reaching equilibrium $\left(t_{1 / 2}\right)$ was not much affected by Rose Bengal; $t_{1 / 2}$ values (min) in the absence and presence of Rose Bengal were estimated to be $1.0 \pm 0.3$ and $1.4 \pm 0.2$, respectively. In contrast, fluorescein caused no significant change in Glu uptake throughout the incubation times tested.

\section{Calcium-dependent Glu release from synaptosomes}

The potassium channel blocker 4-AP was used to induce depolarization of the synaptosomal membrane (Nicholls 1989; McMahon and Nicholls 1991). We focused on the initial rate of $\left[{ }^{3} \mathrm{H}\right] \mathrm{Glu}$ release elicited by 4 -AP in the presence of $\mathrm{Ca}^{2+}$. After $40 \mathrm{~min}$ superfusion, the basal release of $\left[{ }^{3} \mathrm{H}\right] \mathrm{Glu}$ from rat brain synaptosomes was constant for the duration of the experiment $(3 \mathrm{~min})$ and was not affected by replacing $\mathrm{CaCl}_{2}$ with EGTA in the superfusion medium (data not shown). When $\left[{ }^{3} \mathrm{H}\right] \mathrm{Glu}-$ loaded synaptosomes were depolarized by exposure to $50 \mu \mathrm{M}$ 4-AP in CSF containing $\mathrm{Ca}^{2+},\left[{ }^{3} \mathrm{H}\right] \mathrm{Glu}$ release was increased, which was fairly linear up to $1.5 \mathrm{~min}$ (Fig. 4). In the $\mathrm{Ca}^{2+}$-free perfusion medium, no significant increase was observed. The amounts of radioactive compounds released by 4-AP during the $1.5-\mathrm{min}$ superfusion period, in the presence and absence of $\mathrm{Ca}^{2+}$, were $9456 \pm 1252$ and $676 \pm 462$ d.p.m. respectively, over the basal efflux level. Further increase in 4-AP beyond $50 \mu \mathrm{M}$ up to $500 \mu \mathrm{M}$ failed to elicit additional release.

\section{Inhibition of 4-AP-evoked Glu release}

We examined the effect of Rose Bengal and fluorescein on 4-AP-evoked $\left[{ }^{3} \mathrm{H}\right] \mathrm{Glu}$ release from synaptosomes. Rose Bengal at $0.6 \mu \mathrm{M}$ led to complete inhibition of Glu release 


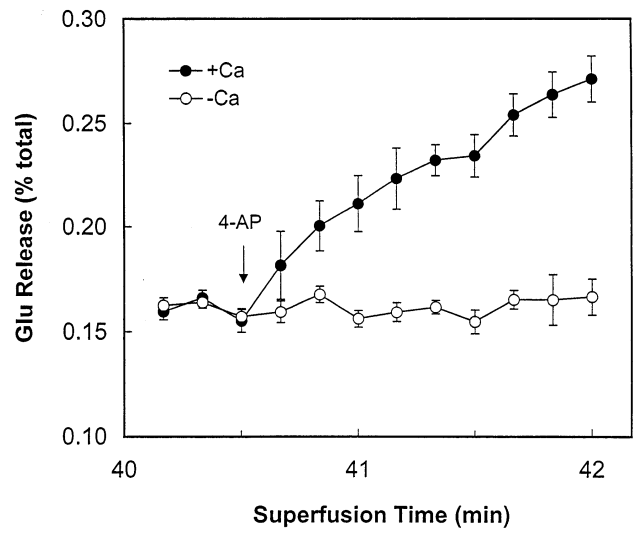

Fig. 4 Effect of 4-AP on Glu release from synaptosomes in the presence or absence of $\mathrm{Ca}^{2+}$. After $\left[{ }^{3} \mathrm{H}\right] \mathrm{Glu}$-loaded synaptosomes were washed for $40.5 \mathrm{~min}$ by superfusion with either normal $\mathrm{Ca}$ containing CSF $(+\mathrm{Ca})$ or $\mathrm{Ca}^{2+}$-free medium in CSF $(-\mathrm{Ca})$, 4-AP $(50 \mu \mathrm{M})$ was applied to depolarize the synaptosomal membrane. The superfusate was collected every $10 \mathrm{~s}$, and radioactivity determined. Values are obtained using four different synaptosomal preparations.

evoked by 4-AP in the presence of $\mathrm{Ca}^{2+}$ throughout the entire period tested, whereas fluorescein failed to affect the 4-AP-evoked release (Fig. 5). These compounds had no effect on calcium-independent release or efflux of Glu (data not shown). These results indicate that Rose Bengal inhibits 4-AP-evoked $\mathrm{Ca}^{2+}$-dependent Glu release. The inhibitory effect was seen up to at least $3 \mathrm{~min}$ after application of 4-AP.

Figure 6 shows 4-AP-evoked $\left[{ }^{3} \mathrm{H}\right] \mathrm{Glu}$ release from synaptosomes as a function of the concentration of Rose

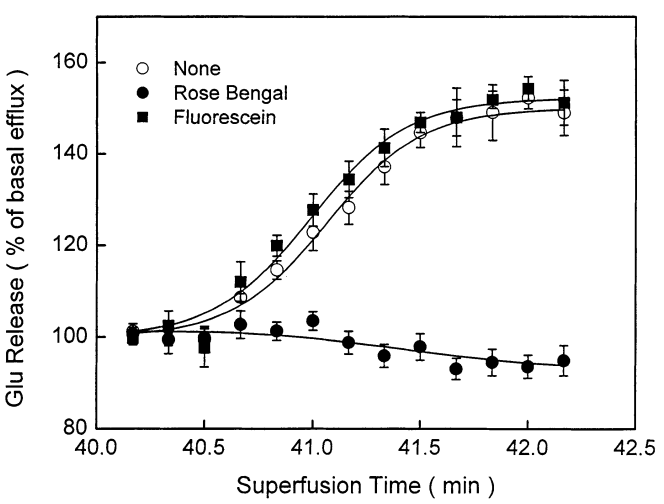

Fig. 5 Effect of presence of Rose Bengal and fluorescein during $\left.{ }^{3} \mathrm{H}\right] \mathrm{Glu}$ loading on time course of subsequent 4-AP-evoked Glu release. Synaptosomes were incubated at $37^{\circ} \mathrm{C}$ for $10 \mathrm{~min}$ with $50 \mathrm{~nm}\left[{ }^{3} \mathrm{H}\right] \mathrm{Glu}$ in the absence or presence of $0.6 \mu \mathrm{m}$ each Rose Bengal or fluorescein in $\mathrm{Ca}^{2+}$-containing CSF, followed by $40 \mathrm{~min}$ superfusion (in absence of test agents), as described in Materials and methods. $\left[{ }^{3} \mathrm{H}\right]$ Glu release was then induced by application of $50 \mu \mathrm{m}$ 4-AP. Values are mean \pm SEM from four separate experiments.

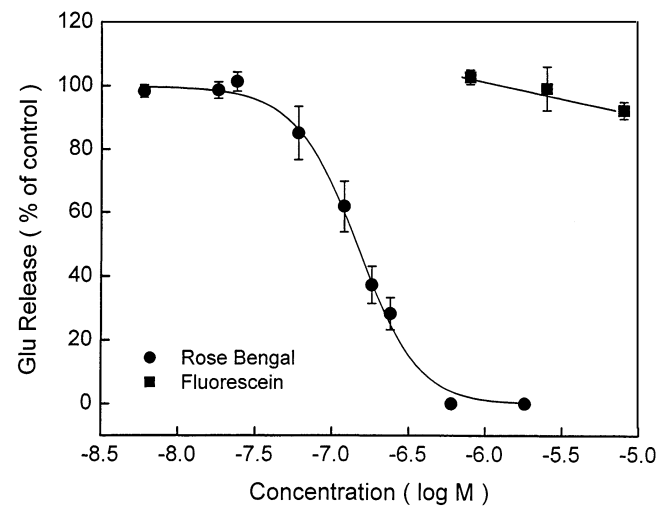

Fig. 6 Effect of presence of various concentrations of Rose Bengal and fluorescein during $\left[{ }^{3} \mathrm{H}\right] \mathrm{Glu}$ loading on subsequent 4-AP-evoked Glu release. Synaptosomes were co-incubated at $37^{\circ} \mathrm{C}$ for $10 \mathrm{~min}$ with $50 \mathrm{~nm}\left[{ }^{3} \mathrm{H}\right] \mathrm{Glu}$ and indicated concentrations of Rose Bengal or fluorescein in CSF. After 40 min superfusion in the absence of test agents, synaptosomes were subjected to 4-AP-induced release. $\left[{ }^{3} \mathrm{H}\right] \mathrm{Glu}$ released by 4 -AP during the 1.5 -min period was determined. Values are mean \pm SEM from four separate experiments.

Bengal and fluorescein. Rose Bengal markedly inhibited the release in a concentration-dependent manner, with an $\mathrm{IC}_{50}$ value of $137 \pm 24 \mathrm{~nm}(n=5)$. However, no significant effect was seen with fluorescein up to $3 \mu \mathrm{m}$. The inhibitory effect of Rose Bengal was unaltered when synaptosomes were incubated with the compound for $30 \mathrm{~min}$ before loading $\left[{ }^{3} \mathrm{H}\right] \mathrm{Glu}$ (data not shown). Rose Bengal (0.01-6 $\left.\mu \mathrm{M}\right)$ did not block 4-AP-induced calcium influx into synaptosomes (data not shown), indicating that Rose Bengal's inhibitory effect on Glu release could not be attributed to prevention of an increase in the synaptosomal calcium concentration, which is required for evoked release of Glu.

Reduction of vesicular Glu content in the synaptosome We have shown that Rose Bengal, but not fluorescein, was remarkably effective in inhibiting not only ATP-dependent Glu uptake into isolated synaptic vesicles, but also 4-APevoked Glu release from synaptosomes. These findings suggested that Rose Bengal, but not fluorescein, reduces the accumulation of Glu in synaptic vesicles within the synaptosome. In an effort to assess this possibility, we examined the effect of Rose Bengal and fluorescein on intrasynaptosomal vesicular $\left[{ }^{3} \mathrm{H}\right] \mathrm{Glu}$ content. We used filtration and centrifugation methods to measure vesicular $\left[{ }^{3} \mathrm{H}\right]$ Glu content in the synaptosome. As shown in Fig. 7(a) (filtration method), Rose Bengal, but not fluorescein, reduced vesicular $\left[{ }^{3} \mathrm{H}\right] \mathrm{Glu}$ content. The $\mathrm{IC}_{50}$ value for the former was determined to be $167 \pm 23 \mathrm{~nm}(n=13)$. Similar dose-response curves and $\mathrm{IC}_{50}$ values were obtained using the centrifugation method (Fig. 7b); the $\mathrm{IC}_{50}$ value was determined to be $137 \pm 52 \mathrm{~nm}(n=4)$. The filtration method, simpler and speedier, yielded less variable 

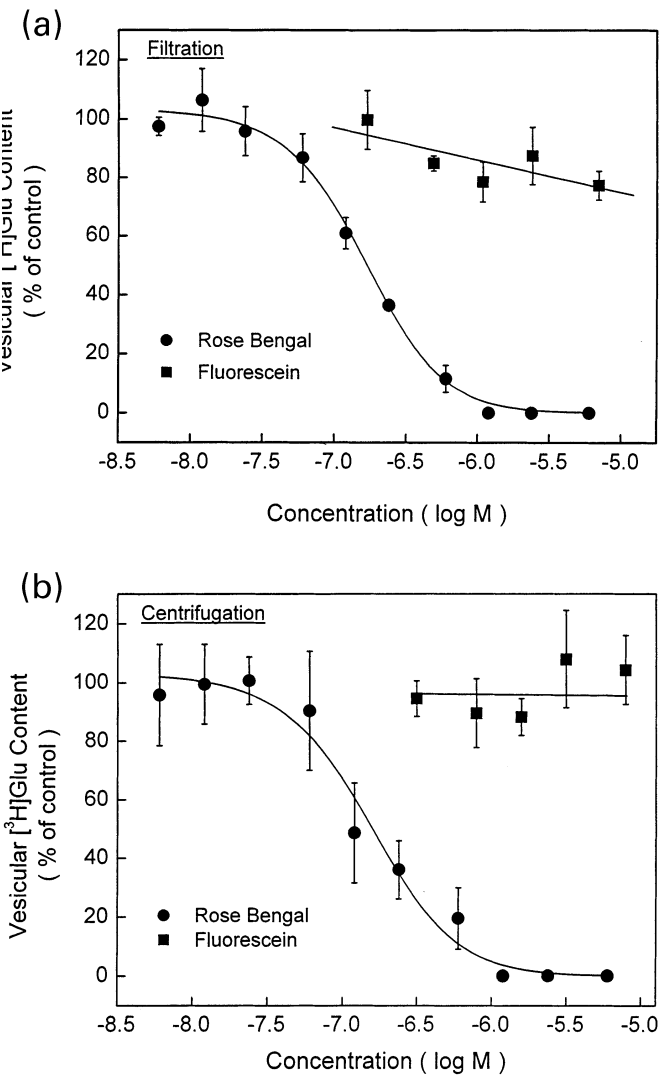

Fig. 7 Effect of various concentrations of Rose Bengal and fluorescein on vesicular $\left[{ }^{3} \mathrm{H}\right] \mathrm{Glu}$ content in the synaptosome. Synaptosomes were incubated at $37^{\circ} \mathrm{C}$ for 10 min with $50 \mathrm{~nm}\left[{ }^{3} \mathrm{H}\right] \mathrm{Glu}$ in the presence of indicated concentrations of Rose Bengal or fluorescein. $\left[{ }^{3} \mathrm{H}\right]$ Glu-loaded synaptosomes were lysed and vesicular $\left[{ }^{3} \mathrm{H}\right] \mathrm{Glu}$ content determined either by the filtration method (a) or the centrifugation method (b), as described in Materials and methods. Values represent the percentage of control values determined in the absence of test compounds, and were obtained from four independent experiments using four separate synaptosome preparations (mean \pm SEM). Control values (\% of the total amount taken up into synaptosomes) for the Rose Bengal and fluorescein dose-response curves determined by the filtration method (a) were $0.541 \pm 0.076$ and $0.490 \pm 0.04$, respectively. Those determined by the centrifugation method (b) were $0.668 \pm 0.025$ and $0.762 \pm 0.046$, respectively.

results, however. This is in accord with the notion that synaptic vesicles in the synaptosomal lysate can be trapped on the filter. This indicates that the simpler filtration method can be used to efficiently estimate vesicular neurotransmitter content. It may be noted that the Rose Bengal doseresponse curve for Glu release is highly similar, if not identical, to that for vesicular Glu content. This argues for the notion that the inhibitory effect of Rose Bengal on Glu release is largely mediated by inhibition of vesicular Glu uptake into synaptic vesicles in the synaptosome. These results are also consistent with our observation that Rose Bengal permeates the synaptosomal membrane with ease.

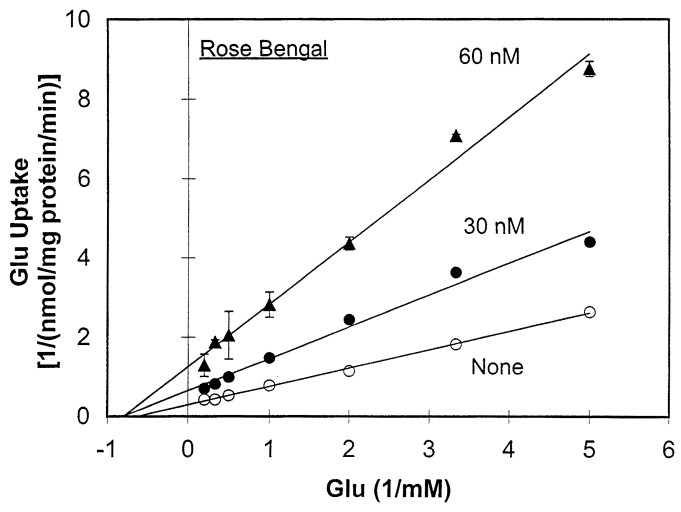

Fig. 8 Effect of Rose Bengal on kinetic parameters of vesicular glutamate uptake system. The RCSV preparation was pre-incubated at $30^{\circ} \mathrm{C}$ for $30 \mathrm{~min}$ in the absence or presence of 30 and $60 \mathrm{~nm}$ Rose Bengal. Vesicular $\left[{ }^{3} \mathrm{H}\right] \mathrm{Glu}$ uptake was initiated by addition of a mixture of ATP (final concentration, $2 \mathrm{~mm}$ ) and various concentrations of unlabeled Glu, together with a fixed amount of $\left[{ }^{3} \mathrm{H}\right] \mathrm{Glu}$ $(74 \mathrm{kBq})$. Uptake was allowed to occur for $2 \mathrm{~min}$ at $30^{\circ} \mathrm{C}$. Values are mean \pm SEM from four separate experiments.

\section{Kinetic analysis for Rose Bengal inhibition of vesicular Glu uptake}

In an effort to understand the mechanism of the inhibition of vesicular uptake by Rose Bengal, kinetic experiments were carried out with isolated synaptic vesicles in the absence and presence of 30 and $60 \mathrm{~nm}$ Rose Bengal. As shown in Fig. 8, Rose Bengal had little, if any, effect on the $K_{\mathrm{m}}$ value for Glu. The $K_{\mathrm{m}}$ value was determined to be $1.61 \pm 0.20 \mathrm{~mm}$ in the absence of Rose Bengal, which is in agreement with values reported previously (Naito and Ueda 1985; Tabb and Ueda 1991; Fykse et al. 1992; Wolosker et al. 1996; Carrigan et al. 1999). The $K_{\mathrm{m}}$ values for Glu in the presence of 30 and $60 \mathrm{~nm}$ were $1.25 \pm 0.16$ and $1.26 \pm 0.21 \mathrm{~mm}$, respectively. In contrast to $K_{\mathrm{m}}, V_{\max }$ was significantly

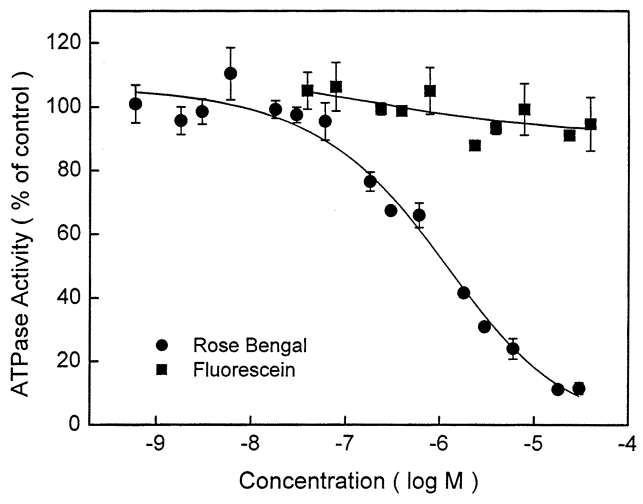

Fig. 9 Effect of various concentrations of Rose Bengal and fluorescein on vesicular ATPase activity. The RCSV preparation was incubated at $30^{\circ} \mathrm{C}$ for $10 \mathrm{~min}$ in presence of indicated concentrations of Rose Bengal and fluorescein, prior to initiation of ATPase activity with addition of ATP, as described in Materials and methods. 
altered by Rose Bengal; $V_{\max }$ values in the presence of 0,30 and $60 \mathrm{~nm}$ Rose Bengal were $3.47 \pm 0.35,1.56 \pm 0.27^{* *}$ and $0.80 \pm 0.12 * * \mathrm{nmol} / \mathrm{min} / \mathrm{mg}$ protein, respectively ${ }^{* *} p<0.01$, compared with the value obtained in the absence of Rose Bengal). Thus, Rose Bengal appears to act as a noncompetitive inhibitor with respect to Glu. The $K_{\mathrm{i}}$ value of Rose Bengal determined from the Dixon plot was $19.4 \pm 0.8 \mathrm{~nm}(n=4)$.

Vesicular ATPase activity and synaptosomal Glu uptake Because vesicular Glu uptake is driven by an electrochemical protein gradient generated by V-type proton-pump ATPase, we tested Rose Bengal for the ability to inhibit this enzyme. Figure 9 shows that, although vesicular $\mathrm{H}^{+}$pump ATPase is subject to inhibition by Rose Bengal, its potency $\left(\mathrm{IC}_{50}=918 \pm 90 \mathrm{nM} ; n=4\right)$ is far below that seen in vesicular Glu uptake inhibition. This indicates that the inhibitory effect of Rose Bengal in the low concentration range is not accounted for by its ability to inhibit $\mathrm{H}^{+}$-pump ATPase at higher concentrations. Fluorescein had no effect up to $50 \mu \mathrm{M}$.

The $\mathrm{Na}^{+}$-dependent Glu uptake system in the plasma membrane is distinct from the vesicular glutamate uptake system (Naito and Ueda 1985; Winter and Ueda 1993). It was hence of interest to determine the effect of Rose Bengal on such a Glu transport system. We tested Rose Bengal for the ability to affect $\mathrm{Na}^{+}$-dependent Glu uptake into synaptosomes. Rose Bengal was also capable of suppressing synaptosomal Glu uptake; however, it showed inhibition at substantially high concentrations compared with those demonstrated to be effective with vesicular glutamate uptake. Rose Bengal's $\mathrm{IC}_{50}$ value for synaptosomal uptake was $2.2 \pm 0.7 \mu \mathrm{M}(n=11)$, which is 60 times higher than that for uptake into isolated synaptic vesicles.

\section{Effect of Rose Bengal on membrane potential}

The observations that Rose Bengal is a noncompetitive inhibitor with respect to glutamate, whereas it exhibits little, if any, inhibition of ATP hydrolysis, led us to consider the possibility that Rose Bengal may achieve glutamate uptake inhibition by dissipating the membrane potential across the synaptic vesicle membrane. The experimental results shown in Fig. 10 indicate that the membrane potential generated by $\mathrm{H}^{+}$-pump ATPase is hardly affected by Rose Bengal at the concentration (37 nM) which causes $50 \%$ inhibition of vesicular glutamate uptake. It is noted, however, that Rose Bengal is capable of dissipating the membrane potential at high concentrations. Its $\mathrm{IC}_{50}$ value for dissipating the membrane potential was estimated to be $\approx 4.3 \mu \mathrm{M}$. It is feasible that Rose Bengal is interacting with two affinity sites $\left(\mathrm{IC}_{50}\right.$ $\approx 0.23$ and $6 \mu \mathrm{M}$ ). In either case, Rose Bengal's $\mathrm{IC}_{50}$ for membrane dissipation is significantly higher than that for vesicular glutamate uptake inhibition, indicating that inhibition of vesicular glutamate uptake by Rose Bengal is (a)
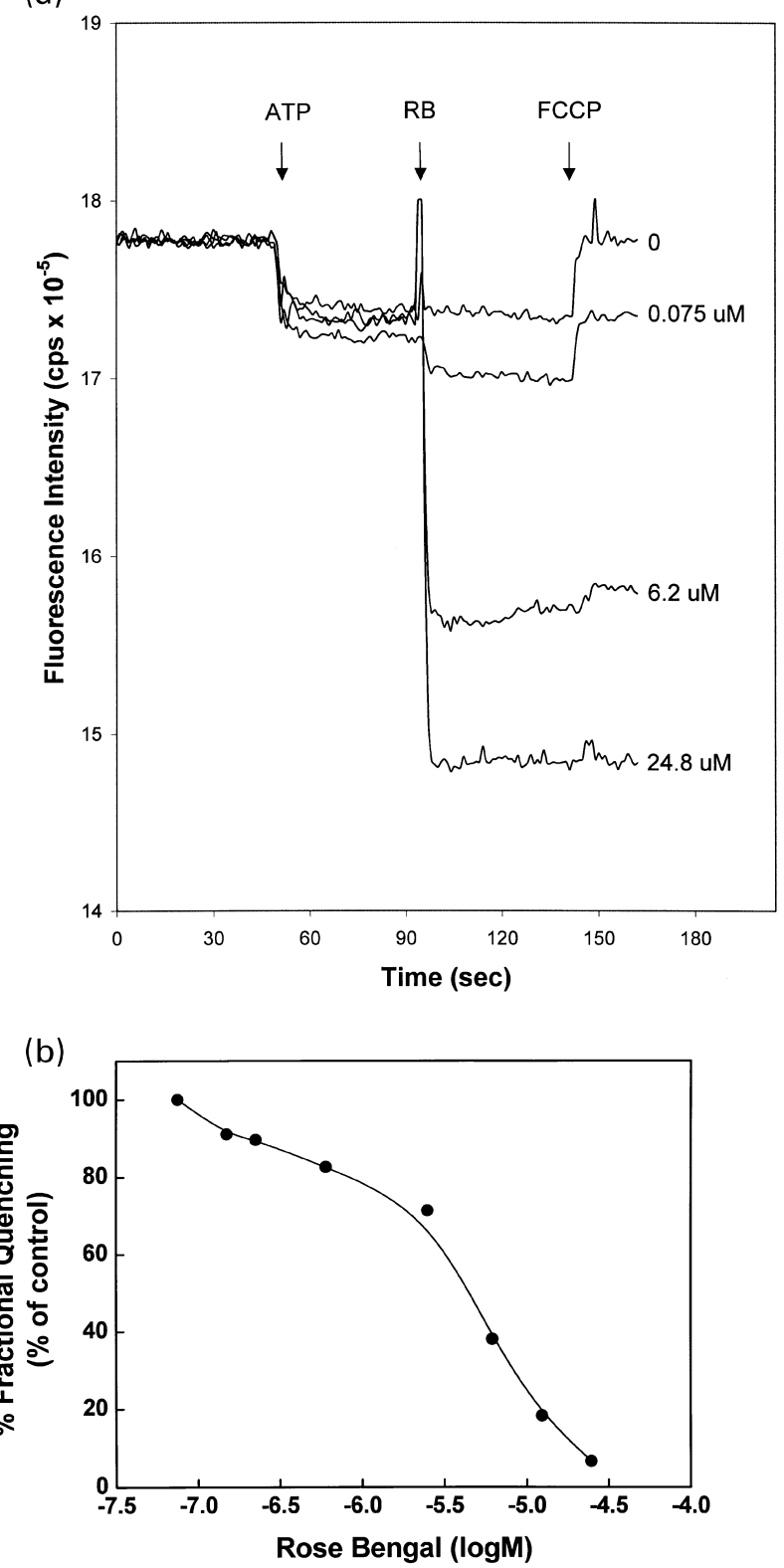

Fig. 10 Effect of various concentrations of Rose Bengal on membrane potential in synaptic vesicles. After oxanol V (1.3 $\mu \mathrm{m})$ was allowed to equilibrate with synaptic vesicles as described in Materials and methods, ATP was added (in $15 \mu \mathrm{L}$ ), resulting in a final concentration of $2 \mathrm{~mm}$. Various amounts of Rose Bengal were then added (in $3 \mu \mathrm{L}$ ), resulting in final concentrations of $0.075,0.15$, $0.225,0.6,2.5,6.2,12.4$ and $24.8 \mu \mathrm{M}$, followed by addition of FCCP (in $1 \mu \mathrm{L}$ ), resulting in a final concentration of $8.33 \mu \mathrm{M}$. Membrane potential was monitored by measuring the fluorescence quenching of oxanol V. Fractional quenching, as defined in Materials and methods, was plotted as a function of the concentration of Rose Bengal. (a) Time course tracing of fluorescence quenching before and after addition of $0.075,6.2$ and $24.8 \mu \mathrm{m}$ Rose Bengal. (b) Membrane potential as a function of various concentrations of Rose Bengal as indicated. 
unlikely to be mediated by dissipating the membrane potential.

\section{Discussion}

We found that Rose Bengal is one of the most potent, noncompetitive inhibitors of Glu uptake into synaptic vesicles, of all the fluorescein-related compounds tested. Unmodified fluorescein was quite ineffective in producing inhibition of vesicular uptake. Rose Bengal, when applied to synaptosomes extracellularly, led to a reduction, with similar degrees of potency, in both vesicular Glu content in the synaptosome and in the amount of released Glu in a calcium- and depolarization-dependent manner. These observations not only support the role of synaptic vesicles in Glu release in the CNS, but also constitute evidence that the amount of exocytotically released Glu can be changed by varying its content in the synaptic vesicle situated within the nerve ending. The potency observed for Rose Bengal's effects on Glu vesicular content and release is lower than that for Glu uptake into isolated synaptic vesicles; this could be ascribed to the negative (inside) resting potential of the synaptosome. Such a potential would prevent quantitative equilibration of Rose Bengal due to its negative charge, requiring a higher extrasynaptosomal concentration in order to achieve the same effective concentration observed with isolated synaptic vesicles. No experiments reported previously measured both exocytotic release and vesicular accumulation of Glu (or any transmitter for that matter), using the same preparation. Our study could provide a lead for the development of a drug to block vesicular glutamate storage and release in vivo. We also examined the effect of Rose Bengal on the initial generation of membrane potential by adding it to the incubation mixture prior to the addition of ATP. It had no significant effect on the process of membrane potential formation, namely, proton translocation by V-type ATPase, at up to $0.225 \mu \mathrm{M}$ (data not shown).

The precise site of action of Rose Bengal remains to be determined. The kinetic data obtained rule out the possibility that it interacts with the Glu-binding site of the vesicular Glu transporter. The potent inhibitory effect of Rose Bengal could not be mediated by inhibition of vesicular $\mathrm{H}^{+}$-pump ATPase. The ATPase activity was hardly affected by those low concentrations which were sufficient to bring about substantial inhibition of vesicular Glu uptake. Moreover, Rose Bengal at $37 \mathrm{~nm}$ (the concentration which caused 50\% inhibition of vesicular glutamate uptake) had no significant effect on dissipation of the membrane potential (Fig. 10), on proton translocation, or on efflux of accumulated $\left[{ }^{3} \mathrm{H}\right] \mathrm{Glu}$ (data not shown). These observations raise the possibility that Rose Bengal is acting on an allosteric site of the vesicular Glu transporter, a site involved in sensing the electrochemical proton gradient or Glu translocation across the vesicle membrane.
Rose Bengal is different in at least four respects from Trypan Blue, the most potent vesicular Glu uptake inhibitor reported to date (Roseth et al. 1998). Firstly, Rose Bengal has a pharmacophore which does not resemble that of Trypan Blue; the former bears the fluorescein backbone structure containing a carboxyl group, whereas the latter is a diazo compound containing amino and sulfon groups like Evans Blue and Chicago Sky Blue. Secondly, Rose Bengal $\left(K_{\mathrm{i}}=19 \mathrm{nM}\right)$ is somewhat more potent than Trypan Blue $\left(K_{\mathrm{i}}=50 \mathrm{~nm}\right)$. Thirdly, the former inhibits vesicular Glu uptake in a noncompetitive manner, whereas the latter competes with Glu. Fourthly, the former is a membrane permeable agent, whereas the latter does not permeate the membrane with ease; this property would render Trypan Blue, when applied extracellularly, ineffective in altering vesicular glutamate content in the nerve ending.

The vesicular Glu uptake system differs from the plasma membrane Glu re-uptake system in several respects including substrate specificity, sensitivity to chloride and the nature of the immediate driving force (Özkan and Ueda 1998). Here, we have shown that Rose Bengal has differential effects on Glu uptake into isolated synaptic vesicles and into synaptosomes; it exhibits more potent inhibition on the former process than on the latter. This significant difference in response to Rose Bengal provides additional evidence for the vesicular Glu uptake system being a distinct molecular entity from the plasma membrane transport system. Thus, the differential effects of Rose Bengal could be used as another parameter to distinguish between these two classes of Glu transport systems.

Our observation that Rose Bengal reduces vesicular $\left[{ }^{3} \mathrm{H}\right] \mathrm{Glu}$ content within the synaptosome and decreases exocytotically released $\left[{ }^{3} \mathrm{H}\right] \mathrm{Glu}$, with similar relatively high potencies $\left(\mathrm{IC}_{50}=137-167 \mathrm{nM}\right)$, is compatible with the notion that Rose Bengal readily permeates the synaptosomal plasma membrane and subsequently elicits these effects. Rose Bengal's inhibitory effect on vesicular uptake could not be ascribed simply to its interaction with the membrane lipid, given the high affinity of Rose Bengal for the vesicular Glu uptake system $\left(K_{\mathrm{i}}=19 \mathrm{~nm}\right)$; it is likely to be mediated by an interaction with a specific hydrophobic domain(s) of a protein component(s) of the ATP-dependent vesicular uptake system.

\section{Acknowledgements}

This work was supported by a grant from the Taisho Pharmaceutical Co., Ltd, Tokyo. We thank Mary Roth for excellent assistance in the preparation of the manuscript.

\section{References}

Bartlett R. D., Esslinger C. S., Thompson C. M. and Bridges R. J. (1998) Substituted quinolines as inhibitors of L-glutamate transport into synaptic vesicles. Neuropharmacology 37, 839-846. 
Bradford H. F. (1995) Glutamate, GABA and epilepsy. Prog. Neurobiol. 47, 477-511.

Bunney B. G., Bunney W. E. Jr and Carlsson A. (1995) Schizophrenia and glutamate, in Psychopharmacology: The Fourth Generation of Progress (Bloom F. E. and Kupfer D. J., eds), pp. 1205-1214. Raven Press, New York.

Burger P. M., Mehl E., Cameron P. L., Maycox P. R., Baumert M., Lottspeich F., De Camilli P. and Jahn R. (1989) Synaptic vesicles immuno-isolated from rat cerebral cortex contain high levels of glutamate. Neuron 3, 715-720.

Carlson M. D., Kish P. E. and Ueda T. (1989) Glutamate uptake into synaptic vesicles: competitive inhibition by bromocriptine. J. Neurochem. 53, 1889-1894.

Carrigan C. N., Esslinger C. S., Bartlett R. D., Bridges R. J. and Thompson C. M. (1999) Quinoline-2,4-dicarboxylic acids: synthesis and evaluation as inhibitors of the glutamate vesicular transport system. Bioorg. Med. Chem. Lett. 9, 2607-2712.

Chapman A. G. (1998) Glutamate receptors in epilepsy. Prog. Brain Res. 116, 371-383.

Choi D. W. (1988) Glutamate neurotoxicity and disease of the nervous system. Neuron 1, 623-634.

Cidon S. and Sihra T. S. (1989) Characterization of a $\mathrm{H}^{+}$-ATPase in rat brain synaptic vesicles. J. Biol. Chem. 264, 8281-8288.

Collingridge G. L. and Singer W. (1990) Excitatory amino acid receptors and synaptic plasticity. Trends. Pharmacol. Sci. 11, 290-296.

Cotman C. W., Monaghan D. T. and Ganong A. H. (1988) Excitatory amino acid neurotransmission: NMDA receptors and Hebb-type synaptic plasticity. Annu. Rev. Neurosci. 11, 61-80.

Coyle J. T. (1996) The glutamatergic dysfunction hypothesis for schizophrenia. Harvard Rev. Psychiat. 3, 241-253.

Feasey K. L., Lynch M. A. and Bliss T. V. P. (1986) Long-term potentiation is associated with an increase in calcium-dependent potassium-stimulated release of $\left[{ }^{14} \mathrm{C}\right]$ glutamate from hippocampus slices: an ex vivo study in the rat. Brain Res. 364, 39-44.

Fonnum F. (1984) Glutamate: a neurotransmitter in mammalian brain. J. Neurochem. 42, 1-11.

Fykse E. M., Christensen H. and Fonnum F. (1989) Comparison of the properties of $\gamma$-aminobutyric acid and L-glutamate uptake into synaptic vesicles isolated from rat brain. J. Neurochem. 52, 946-951

Fykse E. M., Iversen E. G. and Fonnum F. (1992) Inhibition of L-glutamate uptake into synaptic vesicles. Neurosci. Lett. 135, $125-128$

Javitt D. C. and Zukin S. R. (1991) Recent advances in the phencyclidine model of schizophrenia. Am. J. Psychiat. 148, 1301-1308.

Kish P. E. and Ueda T. (1989) Glutamate accumulation into synaptic vesicles. Methods Enzymol. 174, 9-25.

Kish P. E. and Ueda T. (1991) Calcium-dependent release of accumulated glutamate from synaptic vesicles within permeabilized nerve terminals. Neurosci. Lett. 122, 179-182.

Krueger B. K., Forn J. and Greengard P. (1977) Depolarization-induced phosphorylation of specific proteins, mediated by calcium ion influx, in rat brain synaptosomes. J. Biol. Chem. 252, 2764-2773.

Lanzetta P. A., Alvarez L. J., Reinach P. S. and Candia O. A. (1979) An improved assay for nanomole amounts of inorganic phosphate. Anal. Biochem. 100, 95-97.

Lipton S. A. and Rosenberg P. A. (1994) Mechanisms of disease: excitatory amino acids as a final common pathway for neurologic disorders. N. Engl. J. Med. 330, 613-622.

McMahon H. T. and Nicholls D. G. (1991) The bioenergetics of neurotransmitter release. Biochim. Biophys. Acta 1059, 243-264.

Maycox P. R., Deckwerth T., Hell J. W. and Jahn R. (1988) Glutamate uptake by brain synaptic vesicles. J. Biol. Chem. 263, 15423-15428.

Maycox P. R., Hell J. W. and Jahn R. (1990) Amino acid neurotransmission: spotlight on synaptic vesicles. Trends Neurosci. 13, 83-87.

Mehta P. P., Battenberg E. and Wilson M. C. (1996) SNAP-25 and synaptotagmin involvement in the final $\left.\mathrm{Ca}^{2+}\right)$-dependent triggering of neurotransmitter exocytosis. Proc. Natl Acad. Sci. USA 93, 10471-10476.

Meldrum B. (1985) Possible therapeutic applications of antagonists of excitatory amino acid neurotransmitters. Clin. Sci. 68, 113-122.

Moriyama Y., Amakatsu K., Yamada H., Park M.-Y. and Futai M. (1991) Inhibition of neurotransmitter and hormone transport into secretory vesicles by 2-(4-phenylpiperidino) cyclohexanol and 2-bromo- $\alpha$-ergocryptine; both compounds act as uncouplers and dissipate the electrochemical gradient of protons. Arch. Biochem. Biophys. 290, 233-238.

Naito S. and Ueda T. (1983) Adenosine triphosphate-dependent uptake of glutamate into synaptic vesicles. J. Biol. Chem. 258, 696-699.

Naito S. and Ueda T. (1985) Characterization of glutamate uptake into synaptic vesicles. J. Neurochem. 44, 99-109.

Nicholls D. G. (1989) Release of glutamate, aspartate, and $\gamma$-aminobutyric acid from isolated nerve terminals. J. Neurochem. 52, 331-341.

Nicholls D. G. and Sihra T. S. (1986) Synaptosomes possess an exocytotic pool of glutamate. Nature 321, 772-773.

Olney J. W. and Farber N. B. (1995) Glutamate receptor dysfunction and schizophrenia. Arch. Gen. Psychiat. 52, 998-1007.

Özkan E. D. and Ueda T. (1998) Glutamate transport and storage in synaptic vesicles. Jpn. J. Pharmacol. 77, 1-10.

Özkan E. D., Lee F. S. and Ueda T. (1997) A protein factor that inhibits ATP-dependent glutamate and $\gamma$-aminobutyric acid accumulation into synaptic vesicles: purification and initial characterization. Proc. Natl Acad. Sci. USA 94, 4137-4142.

Roseth S., Fykse E. M. and Fonnum F. (1995) Uptake of L-glutamate into rat brain synaptic vesicles: effect of inhibitors that bind specifically to the glutamate transporter. J. Neurochem. 65, 96-103.

Roseth S., Fykse E. M. and Fonnum F. (1998) Uptake of L-glutamate into synaptic vesicles: competitive inhibition by dyes with biphenyl and amino- and sulphonic acid-substituted naphthyl groups. Biochem. Pharmacol. 56, 1243-1249.

Storm-Mathisen J., Leknes A. K., Bore A. T., Vaaland J. L., Edminson P., Haug F.-M. S. and Ottersen O. P. (1983) First visualization of glutamate and GABA in neurons by immunocytochemistry. Nature 301, 517-520.

Tabb J. S. and Ueda T. (1991) Phylogenetic studies on the synaptic vesicle glutamate transport system. J. Neurosci. Sci. 11, 1822-1828.

Tabb J. S., Kish P. E., Van Dyke R. and Ueda T. (1992) Glutamate transport into synaptic vesicles. Roles of membrane potential, $\mathrm{pH}$ gradient, and intravesicular pH. J. Biol. Chem. 267, $15412-15418$.

Ueda T. (1986) Glutamate transport in the synaptic vesicle, in Excitatory Amino Acids (Roberts P. J., Storm-Mathisen J. and Bradford H. F., eds), pp. 173-195. Macmillan, London.

Watkins J. C., Krogsgaard-Larsen P. and Honore T. (1990) Structure-activity relationships in the development of excitatory amino acid receptor agonists and competitive antagonists. Trends Pharmacol. Sci. 11, 25-33.

Winter H. C. and Ueda T. (1993) Glutamate uptake system in the presynaptic vesicle: glutamic acid analogs as inhibitors and alternate substrates. Neurochem. Res. 18, 79-85.

Wolosker H., de Souza D. O. and de Meis L. (1996) Regulation of glutamate transport into synaptic vesicles by chloride and proton gradient. J. Biol. Chem. 271, 11726-11731.

Yoneda Y. and Ogita K. (1989) Microbial methodological artifacts in $\left[{ }^{3} \mathrm{H}\right]$ glutamate receptor binding assays. Anal. Biochem. 177, 250-255.

Zorumski C. F. and Olney J. W. (1993) Excitotoxic neuronal damage and neuropsychiatric disorders. Pharmac. Ther. 59, 145-162. 